\title{
The effect of novel environments on CS extinction in a conditioned suppression paradigm
}

\author{
PETER V. HANFORD \\ Institute of Psychiatric Research, Indiana University School of Medicine, Indianapolis, Indiana 46202 \\ and Indiana Purdue University, Indianapolis, Indiana 46205
}

DALLAS E. MULVANEY

Institute of Psychiatric Research, Indiana University School of Medicine, Indianapolis, Indiana 46202 and New Castle State Hospital, New Castle, Indiana 47362

and

\section{DEBORAH A. KELFER \\ Indiana Purdue University, Indianapolis, Indiana 46205}

\begin{abstract}
Twelve rats were trained to produce food by barpressing according to a variable-interval schedule of reinforcement. When their rates of responding had stabilized, a conditioned suppression paradigm was implemented. After asymptotic suppression was obtained and after stabilization of non-CS rates of responding, the CS for all the animals was extinguished in a novel environment, with a novel response being required for food production. When extinction of the conditioned emotional response was complete in the novel environment (i.e., a complete absence of suppression), the animals were returned to the original training environment and given the CS alone. It was found that the animals showed suppression to the CS in the original environment. It was concluded that the behavioral control of a CS is influenced by the ambient environment during initial learning.
\end{abstract}

Solomon, Kamin, and Wynne (1953) studied the problem of extinguishing a set of stimuli that had been paired with shock. Experiment 3 of their series of studies involved the pairing of a light-off conditioned stimulus (CS) with shock in one side of a shuttlebox. None of the 23 dogs, when given CS-only trials, showed any extinction. When extinction did not follow from the CS-only procedure, these investigators arranged to keep the animals in the presence of the CS for its entire duration. Ten trials a day were given each dog for the duration of the experiment. For Trials 4-7 during extinction, a glass barrier was placed between the CS conditioned side and the "safe" side of the shuttlebox. The glass wall prevented the dog from escaping the CS. The animals received a minimum of 50 glass barrier extinction trials in addition to 50 nonglass barrier trials. On the trials with the glass barrier, the dogs did not exhibit emotionality;

The authors would like to express their gratitude to L. C. Fitzhugh and B. R. Wagner for their support, to William Wolff for his encouragement and help, to Richard L. Solomon, John W. Moore, and Kay Mueller for several helpful suggestions, and to Bettye Barnes, Arvella Mastin, and Janet Justice for their typing of the manuscript. Requests for reprints may be sent to Peter V. Hanford, Department of Psychology, Indiana University-Purdue University at Indianapolis, Indianapolis, Indiana 46205, or to Dallas E. Mulvaney, New Castle State Hospital, New Castle, Indiana 47362. that is, they remained calm and did not try to escape for the last 20 to 30 trials with the glass barrier. However, on the trials without the glass barrier, 1-3 and 8-10, the animals continued to escape.

In brief, when the glass barrier was present it appeared that the CS had extinguished; however, when tested under conditions of ordinary extinction, the animals showed little sign of extinction. These observations raise the question of what are the conditions of extinction of a CS. Apparently, if the CS is extinguished in a modified environment, the animals are capable of making the distinction, thus altering the course of CS extinction (cf. Bouton \& Bolles, 1979).

In a subsequent study that methodologically bridges the Solomon et al. (1953) study with the present study, Kamin, Brimer, and Black (1963) extinguished a CS in an avoidance learning situation using rats and then tested the "fear" associated with the CS in a conditioned suppression paradigm. They found that the fear indexed by the suppression ratio was inversely related to the number of extinction trials.

Whereas Kamin et al. (1963) and Solomon et al. (1953) were primarily interested in the extinction of the $\mathrm{CS}$, the present study, using extinction as a procedural manipulation, was concerned with determining the role that the conditioning environment plays in the control of conditioned suppression. Both Kamin et al.(1963) and 
Solomon et al. (1953) used an avoidance paradigm to train and extinguish the CS. In addition, Kamin et al. (1963) tested the strength of the CS in a conditioned suppression paradigm. The present experiment differs from that of Kamin et al. (1963) in that a classical procedure was utilized for both training and testing.

\section{METHOD}

\section{Subjects}

Twelve albino (Wistar) male rats whose body weight had been reduced to $80 \%$ of their free-feeding weight served as subjects. They were approximately 9 months of age at the beginning of the experiment.

\section{Apparatus}

Two experimental chambers were utilized in this study. One was constructed of wood, the second of clear plastic. Both boxes measured $25.3 \times 23 \mathrm{~cm}$ and were $17 \mathrm{~cm}$ from the grid floor to the top of the box. During the initial phase of the experiment, the floor of both boxes consisted of brass rods $2.7 \mathrm{~mm}$ in diameter. In the second phase of the experiment, the grid floor of the plastic box was covered with a sheet of translucent plastic and the grid floor of the wood box was replaced with a plywood sheet. The front panel of the plastic box was made of aluminum and contained two bars located $7.5 \mathrm{~cm}$ above the grid floor. In this study, only the bar on the right side of the panel was used. A light was located above and to the right of the bar; a second light was located over the wall where the solenoidoperated liquid dipper was located. A houselight was located outside the plastic wall on the right side of the panel. A relay, which served as a clicker and a speaker, was mounted behind the aluminum panel. A nose key and a houselight were mounted on the front panel of the wood box. The liquid dipper mechanism and relay were attached behind the front panel. The nose key was a pigeon key $2.5 \mathrm{~cm}$ in diameter, made of white translucent plastic, that could be transilluminated from the rear by a $6-\mathrm{W}$ bulb. The key was centered $6.2 \mathrm{~cm}$ from the grid floor. A houselight was located on top of the front panel.

\section{Procedure}

The rats were divided into two groups of six subjects each, and each group received daily sessions. One group was trained to nose key in the wooden box containing a nose key, a speaker, a liquid magazine feeder, and a grid floor. The other group of six subjects was trained to barpress in a plastic box containing a bar, a speaker, a liquid magazine feeder, and a grid floor. Nose keying and barpressing in the respective boxes produced a 3 -sec access to milk on a variable-interval (VI) 1-min schedule of reinforcement. When the behavior of an animal had stabilized for 4 days with no consistent trend in the rate of responding, the conditioned suppression stimulus, a white noise of 1-min duration, was superimposed on the VI 1-min food schedule. A maximum of six CS-UCS pairings were programmed for each session on a VI 10-min schedule. Sessions terminated with the delivery of the 50th reinforcement. The average session length for the 12 animals was $81.5 \mathrm{~min}$. Initially, the white noise was presented without shock to test novelty effects. During suppression training, the 1-min white noise was presented in both boxes simultaneously and was terminated by a 1-sec .8-mA shock delivered to the grid floor of each box simultaneously.

The conditioned suppression paradigm remained in effect until all the animals showed suppression during the white noise and responding during the non-CS periods had stabilized. Suppression was measured by the ratio: rate of responding during white noise divided by rate of responding during white noise plus rate of responding $1 \mathrm{~min}$ prior to the onset of the white noise
Table 1

Summary of Procedures

\begin{tabular}{lc}
\hline & N of Sessions \\
\hline Shape Original Response & $4-7$ \\
Baseline VI 60 sec & $19-30$ \\
White Noise Test & 14 \\
Conditioned Suppression Paradigm & $25-33$ \\
Shape Novel Response & $5-7$ \\
VI 60 sec in Novel Box & $15-22$ \\
Novel Stimulus in Novel Box & $7-8$ \\
CS Extinction in Novel Box & 14 \\
CS Extinction in Original Box & $7-17$ \\
\hline
\end{tabular}

(Annau \& Kamin, 1961). Thus a ratio of .5 indicates no suppression and a ratio of .0 complete suppression. A minimum of five sessions and a maximum of seven sessions were required to achieve the suppression criterion of .15; however, several more sessions were required to stabilize non-CS responding (see Table 1).

When all the animals showed a suppression ratio (SR) of .15 or below and had stabilized during non-CS time, they were switched to the other box (i.e., plastic to wood and wood to plastic). The grid floors of both boxes were removed and replaced with a wood floor in the wood box and a plastic floor in the plastic box. The subjects were trained to make the appropriate response for food by hand shaping. At the conclusion of shaping, the food schedule of reinforcement was VI 1-min, as in the previous portion of the experiment.

When the behavior of an animal had stabilized for 4 consecutive days with no consistent trend in the rate of responding, a 1-min novel stimulus was introduced to test for suppression. The novel stimulus for both boxes was a $3 / \mathrm{sec}$ clicker (relays operated by an electronic timer). The clickers were programmed on the same VI 10-min schedule as the CS during suppression training.

When the behavior stabilized during the novel stimulus test (7-8 sessions, see Table 1), the original CS replaced the novel stimulus and was presented on the same schedule until the animals showed no suppression. After an animal showed an extinction SR of .40 or higher to the CS in the novel environment, the next session, the following day, it was returned to the original training environment. Again, the CS was presented without shock on the same schedule until the animal showed extinction (i.e., $\mathrm{SR}=.40$ or higher).

Table 1 lists the order of each stage of the experiment and the number of sessions in each stage.

\section{RESULTS}

Table 2 shows the median 3-day SRs of five different times of the experiment. In row 1 the medians for the last 3 days of conditioned suppression training are presented. It can be seen that all the subjects suppressed their responding during CS presentation.

Row 2 shows the median data for the first 3 days of novel stimulus test in the novel environment. It can be seen that very little suppression occurred to the novel stimulus. The mean of the 12 SR medians was .51 .

Row 3 shows the median data of the first 3 days of extinction in the novel chamber. In general, the animals showed complete to moderate suppression. The mean of the 12 SR medians was .16 .

Row 4 shows the median data of the last 3 days of 
Table 2

Suppression Ratios (SRs) During Training, Extinction in the Novel Box, and Test in the Original Box

\begin{tabular}{lcccccccccccc}
\hline & \multicolumn{10}{c}{ Subjects } \\
\cline { 2 - 12 } & 1 & 2 & 3 & 4 & 5 & 6 & 7 & 8 & 9 & 10 & 11 & 12 \\
\hline SR in Original Box & .04 & .00 & .08 & .06 & .04 & .04 & .00 & .01 & .02 & .00 & .05 & .00 \\
SR to Novel Stimulus in Novel Box & .51 & .52 & .54 & .48 & .44 & .53 & .47 & .38 & .62 & .61 & .58 & .55 \\
SR in Novel Box & .35 & .11 & .10 & .07 & .00 & .00 & .33 & .21 & .30 & .00 & .00 & .48 \\
SR After Extinction in Novel Box & .62 & .45 & .56 & .54 & .50 & .40 & .49 & .44 & .57 & .56 & .51 & .54 \\
SR Test in Original Box & .03 & .02 & .15 & .33 & .07 & .33 & .00 & .00 & .00 & $*$ & .05 & .47 \\
\hline
\end{tabular}

Note-The data in rows 1 and 4 are medians for the last 3 days of training and the data in rows 2, 3, and 5 are medians for the first 3 days of their respective conditions. Subject 10 was dropped from the last condition because he quit responding entirely.

extinction in the novel chamber. In general, the animals showed complete to moderate extinction. The mean of the 12 SR medians was .51 .

Row 5 shows the median data of the first 3 days of extinction in the original training boxes. Eight of the subjects showed suppression and three subjects showed little or no suppression. The mean of the 11 medians was .13. The median rate of response for the last five sessions of the conditioning phase of the experiment was 12.34 . The median rate of response for the first session in which the animals were returned to the original box was 10.34. These rates indicate that there was not a significant variation between these two conditions of the experiment.

\section{DISCUSSION}

The present results parallel those of Bouton and Bolles (1979) and Solomon et al. (1953): Modification of the environment during extinction effects the extinction of the conditioned response. The results of this study and the Solomon et al. study suggest that the effective CS consists of the stimulus programmed by the experimenter plus the background stimuli present during the original conditioning. White noise as a CS in one environment is not perceived as the same CS in another environment.

Bouton and Bolles (1979) demonstrated that a CS extinguished in an environment different from that in which the CS was paired with the UCS retained its capacity to suppress spontaneous motor activity when the subject was returned to the original conditioning environment. It is important to note three major differences in procedure between the present study and the Bouton and Bolles (1979) study. In their study, all animals were first trained to barpress in a standard operant chamber; then all animals were given CS-UCS pairings in an activity chamber, and all extinction trials were given in one of the two chambers. This means, in contrast to the present study, that extinction was conducted in a familiar environment. Dexter and Merrill (1969) demonstrated that preexposure to a CS retarded the strength of conditioned suppression. It can be argued that since contextual stimuli are conditionable (Dweck \& Wagner, 1970; Kremer, 1974; Odling-Smee, 1975, 1978), one would expect that, after preexposure to the operant chamber, subsequent extinction of the CS in the same chamber would be modified.

A second difference is that the present study used suppression of a conditioned operant response (barpress or nose key) to assess conditioned suppression, whereas Bouton and Bolles used interruption of spontaneous motor activity.

Third, the present study included a much larger number of training, extinction, and testing trials than the Bouton and Bolles study. The intent of the present work was to condition the CS to asymptotic values in order to produce, if possible, a unique association with the UCS, thereby mimimizing extraneous environmental associations.

Indeed, Rescorla and Wagner (1972) discuss the interaction of context and CS conditioning. However, these authors argue that, when utilizing a specific stimulus as a conditioned stimulus, the behavior controlled by the CS will be inversely related to the control exerted by the contextual stimuli in the conditioning environment; as the correlation between the CS and UCS increases, the control of behavior by the CS increases. Data obtained by Rescorla (1972) and Wagner (1969) support this account. If one presumes that the 125 pairings of the CS and UCS of the present study were sufficient to reach asymptotic associative strength, then the Rescorla-Wagner model would predict that the CS in the present study controlled the behavior and the contextual cues would have little, if any, associative strength.

The results of the present study do not support that hypothesis. The strong resumption of conditioned suppression in the original conditioning environment following extinction of the $\mathrm{CS}$ in the novel environment indicates that the effective CS is the CS presented by the experimenter and the contextual cues that accompany it. In other words, conditioning a CS to near asymptotic levels does not necessarily block contextual conditioning.

\section{REFERENCES}

Annau, Z., \& Kamin, L. J. The conditioned emotional response as a function of intensity of the US. Journal of Comparative and Physiological Psychology, 1961, 54, 428-432.

Bouton, M. E., \& Bolles, R. C. Contextual control of the extinction of conditioned fear. Learning and Motivation, 1979, $10,445-466$.

Dexter, W. R., \& Merrill, H. R. Role of contextual discrimination in fear conditioning. Journal of Comparative and Physiological Psychology, 1969, 69, 677-681.

Dweck, C. S., \& Wagner, A. R. A. Situational cues and correlation between conditioned stimulus and unconditioned stimulus as determinants of the conditioned emotional response. Psychonomic Science, 1970, 18, 145-147.

Kamin, L. J., Brimer, C. J., \& Black, A. H. Conditioned suppression as a monitor of fear of the CS in the course of avoidance training. Journal of Comparative and Physiological Psychology, 1963, 56, 497-501.

KREMER, E. F. The truly random control procedure: Conditioning to static cues. Journal of Comparative and Physiological Psychology, 1974, 86, 700-707.

Odung-Smee, F. J. The role of background stimuli during Pavlovian conditioning. Quarterly Journal of Experimental Psychology, 1975, 27, 201-209. 
Odling-Smee, F. J. The overshadowing of background stimuli by an informative CS in aversive Pavlovian conditioning with rats. Animal Learning \& Behavior, 1978, 6, 43-51.

Rescorla, R. A. "Configural" conditioning in discrete trial bar pressing. Journal of Comparative and Physiological Psychology, 1972, 79, 307-317.

Rescorla, R. A., \& Wagner, A. R. A. A theory of Pavlovian conditioning: Variations in the effectiveness of reinforcement and nonreinforcement. In A. H. Black \& W. F. Prokasy (Eds.), Classical conditioning II: Current research and theory. New York: Appleton-Century-Crofts, 1972.
Solomon, R. L., Kamin, L. J., \& Wynne, L. C. Traumatic avoidance learning: The outcomes of several extinction procedures with dogs. Journal of Abnormal and Social Psychology, 1953, 48, 291-302.

WAGNER, A. R. A. Stimulus selection and a "modified continuity theory." In G. H. Bower \& J. T. Spence (Eds.), The psychology of learning and motivation (Vol. 3). New York: Academic Press, 1969.

(Received for publication August 19, 1980.) 